\title{
MENJUNJUNG ASAS KEADILAN BERUMAH TANGGA ANTARA KEDUA PIHAK KELUARGA DENGAN PELAKSANAAN SISTEM PERKAWINAN PADA GELAHANG DI BALI
}

\author{
Ni Made Budiasih S.Ag, M.Ag \\ Dosen Jurusan Komunikasi dan Penerangan Institut Hindu Dhama Negeri Denpasar \\ madebudiasiih@gmail.com
}

\begin{abstract}
Balinese perception of marriage in gelahang including positive, because it is seen as a reality that already exist in society, and never questioned. The inheritance system in the family that carries out the marriage in gelahang in Bali basically adheres to the parental principle, namely the inheritance system that inherits the family of the male and female families. The pattern of parenting in the family formed through marriage in gelahang generally chooses the pattern of democratic care that is characterized by the rights and obligations of parents and children is the same, in the sense that they are complementary. The process of execution of marriage in gelahang is not different from ordinary marriage process, and generally executed by the process of marriage, which was preceded by dating period. In the marriage at gelahang there are two relatively similar ceremonies, namely at the residence of the bridegroom and at the residence of the bride's. The equation of marriage in gelahang with marriage nyentana namely: equally an alternative marriage, based on love the same love, there are religious witnesses (banten ceremony) and social witness (community) and both want to get offspring. While the difference is that marriage in gelahang status of men and women there is no change in status, so often called parental. The positions of born children are held jointly, unless there is another agreement. An important aspect of marriage in gembles that is rarely encountered is an agreement between husband and wife witnessed by the families of both parties, the agreement can be written and can be verbal.
\end{abstract}

Keywords: marriage in gelahang, nyentana, parental.

\section{PENDAHULUAN}

Manusia yang dilahirkan ke dunia, sebagai makhluk yang memiliki akal, budhi, dan manah agar dapat menolong dirinya sendiri dari kesulitankesulitan yang dihadapinya. Dari sisi lain dinyatakan bahwa manusia itu adalah makhluk yang lemah, karena memiliki kemampuan yang terbatas, oleh sebab itu maka manusia itu sendiri akan selalu memohon perlindungan kehadapan Sang Pencipta.

Demikian juga manusia adalah makhluk sosial arena itu tidak akan bisa hidup sendiri tanpa bantuan makhluk atau manusia yang lain. Dengan adanya kenyataan inilah manusia tersebut membentuk suatu masyarakat, agar mempunyai tempat untuk dapat melaksanakan pergaulan mencari pengalaman dan pendidikan untuk meningkatkan dirinya dari kebodohan menuju tingkat intelektualitas yang lebih tinggi.

Undang-Undang No.1 Tahun 1974 tentang Perkawinan menyatakan bahwa perkawinan adalah ikatan lahir bathin antara seorang pria dengan seorang wanita sebagai suami istri dengan tujuan membentuk keluarga (rumah tangga) yang bahagia dan kekal berdasarkan Ketuhan-an Yang Maha Esa. Ada beberapa sistem kekeluargaan 
dalam masyarakat. (1) Sis-tem kekeluargaan patrilineal, yaitu sistem kekeluargaan yang didasarkan atas perta-lian darah menurut garis bapak. Dalam sistem ini si isteri akan menjadi warga masyarakat dari pihak suaminya. (2) Sistem kekeluargaan matrilineal, yaitu sistem kekeluargaan yang didasarkan atas perta lian darah menurut garis ibu. Dalam sistem ini si isteri tetap tinggal dalam klan atau golongan keluarganya.

Pada umumnya masyarakat Bali menganut sistem perkawinan patrilineal, yang mengambil bentuk perkawinan biasa atau perkawinan nyentana. Dalam perka-winan biasa, si gadis meninggalkan ru-mahnya dan diajak ke rumah keluarga pengantin laki-laki. Sedangkan dalam perkawinan nyentana, mempelai laki-laki yang statusnya berubah menjadi perem-puan (predana) ikut pada keluarga mempelai wanita yang telah dikukuhkan sebagai laki-laki (purusa). Tujuan pokok dari perkawinan nyentana adalah untuk mengusahakan agar sang istri (selaku anak perempuan) memperoleh kedudukan selaku sentana purusa (laki-laki) atau pelanjut keturunan dalam lingkungan keluarganya. Dalam sistem purusa, anak perempuan biasanya merupakan sentana yang berstatus lemah atau labil, tak dapat tegak di rumah asalnya. Karena itu dengan perkawinan nyentana selaku sara-na, maka sentana perempuan itu dikukuh-kan (dirajegkan) sebagai laki-laki (purusa). Dengan demikian sentana rajeg berarti anak perempuan selaku sentana yang biasanya tidak kuat, dengan dan melalui perkawinan nyentana selaku rajegnya, dijadikan sentana yang kokoh berstatus purusa. Singkatnya sentana yang lemah diberi rajeg supaya kokoh.

Selain bentuk perkawinan di atas, di Bali juga dikenal bentuk perkawinan pada gelahang, yaitu perkawinan antara laki-laki dan perempuan yang sama-sama bersta-tus purusa (laki-laki). Menurut Sudarsana (dalam Windia 2009) bahwa perkawinan pada gelahang di beberapa tempat disebut dengan istilah yang berbeda-beda. Di
Banjar Poh Manis Penatih, Denpasar disebut dengan negen dadua, di Banjar Kukub, Perean, Tananan disebut mapa-nak bareng, di Desa Belumbang, Keram-bitan, disebut nadua umah. Walaupun penyebutan berbeda-beda, namun makna yang terkandung dari sebutan itu adalah perkawinan pada gelahang atau gelahang bareng (miliki bersama). Lebih lanjut Sudarsana menjelaskan perkawinan pada gelahang ini sangat didasarkan oleh kekerabatan yang sama, karena waris pewaris dikemudian hari. Perkawinan pada gelahang adalah perkawinan yang dilakukan oleh pasangan suami istri yang upacara pabeyakaonan (sahnya perkawin-an) dilakukan di tempat kediaman masing-masing pasangan. Perkawinan pada gelahang menganut sistem parental, karena hak dan kewajiban laki-laki dengan perempuan sama (seimbang). Alasan utama dilaksanakan perkawinan pada gelahang adalah karena lakilaki (purusa) tidak mau diubah statusnya menjadi perempuan (pradana). Perkawinan pada gelahang dapat menyelamatkan keturunan bagi mereka yang tidak memiliki anak laki-laki, manakala mempelai laki-laki juga tidak berkenan untuk nyentana. Secara sederhana dapat dikatakan bahwa penye-bab utama munculnya model perkawinan ini karena ada satu keluarga yang memiliki anak perempuan saja dan pihak lakilaki tetap menginginkan agar berstatus purusa, karena terikat dengan tanggung jawab. Perkawinan seperti ini memiliki landasan hukum yang kuat, seperti termuat dalam Weda dan Susastra Hindu lainnya. Perkawinan model ini sejalan dengan penghormatan terhadap perempuan sebagaimana terdapat dalam kitab suci Weda (perspektif gender) maupun per-spektif nilai-nilai kemanusiaan

\section{PEMBAHASAN}

Perkawinan Pada Gelahang adalah salah satu sistem perkawinan di Bali yang berbeda dari biasanya karena baik suami maupun istri bertindak sebagai Purusa. Perkawinan Pada Gelahang tidak 
bertentangan dengan Adat Bali maupun Ajaran Agama Hindu. Adapun dampak secara nyata dari sistem perkawinan ini yaitu: pasutri memiliki beban ganda dalam melaksanakan kewajiban dalam Desa Pakraman seperti ayah-ayahan di pura, banjar, dll. Jika pasutri hanya memiliki satu anak, maka beban anak akan berlipat ganda apalagi anak tersebut akan menikah.

Meskipun sistem perkawinan Pada Gelahang baru popular di kalangan masyarakat Bali, namun sistem perkawinan ini ternyata sudah dikenal sejak dahulu dalam sistem kehidupan sosial masyarkat Bali. Hal ini karena fenomena nak tunggal tidak hanya terjadi pada masa modernisasi seperti saat ini, tapi sudah ada sejak zaman dulu kala.

Menurut penelitian yang dilakukan Guru Besar Fakultas Hukum Universitas Udayana, Prof Wayan P. Windia, tercatat perkawinan Pada Gelahang di Bali sudah dilakukan sejak tahun 1945 silam. "Sistem perkawinan ini sudah dikenal oleh masyarakat Bali, dan tercatat pada tahun 1945 perkawinan pade gelahang sudah dilakukan," jelasnya.

Berdasar data yang diberikan Prof Windia, pelaksanaan perkawinan pada gelahang berdasarkan tahun pelaksanaannya dapat dikelompokan menjadi beberapa kelompok. Yakni sebelum tahun 1945, antara tahun 1946-1974, antara tahun 1975-200 dan sesudah tahun 2001.

Dipilihnya tahun 1945 sebagai titik awal pijakan karena tahun 1945 sebagai tonggak awal lahirnya bangsa Indonesia. Sehingga setelah tahun 1945 sistem hukum di Republik Indonesia dikatakan Prof Windia sudah berbeda dengan sistem hukum pada masa penjajahan Belanda. "Hal ini juga membawa pengaruh pada pola berfikir masyarakat, termasuk juga pada tata cara pelaksanaan perkawinan yang lebih modern," lanjutnya.

Sedangkan tahun 1974 dianggap penting karena pada tahun 1974 mulai diberlakukannya Undang-Undang Nomor 1 Tahun 1974 tentang
Perkawinan. Sehingga tahun ini menjadi tahun yang penting dalam sistem perkawinan di Bali, karena selain disahkan oleh hukum adat dan hukum Hindu, perkawinan di Bali juga harus dilakukan sesuai dengan ketentuan yang ada di dalam UU No 1 Tahun 1974.

Lantas bagaimana perkembangan Perkawinan Pada Gelahang dari tahun ke tahun?

Menurut Data yang diberikan Prof Windia, sejak masa kolonial sampai tahun 1945 dalam penelitian tersebut diketahui ada empat pasangan di Bali yang melakukan perkawinan Pada Gelahang. Pada tahun 1946-1974 tercatat ada lima pasangan yang tercatat melakukan perkawinan Pada Gelahang. Pada tahun 1975-2000 tercatat ada sebanyak 9 pasangan yang melakukan perkawinan Pada Gelahang. Dan pada tahun 2000 sampai dengan 2008 tercatat sebanyak 10 pasang suami instri yang melakukan perkawinan Pada Gelahang.

Berdasar data tersebut, Prof Windia menyimpulkan jika di era modern ini pelaksanaan perkawinan Pada gelahang mengalami peningkatan yang signifikan. "Banyak penyebab yang kenapa perkawinan pada Gelahang ini dilakukan, salah satunya adalah kedua pasangan berstatus anak tunggal. Selain itu karena pihak perempuan tidak memiliki saudara laki-laki sementara saudara perempuannya sudah kawin keluar dan pihak lakilaki adalah anak tunggal," paparnya.

Dari pelaksanaan Perkawinan Pada Gelahang tersebut, sejak penelitian terakhir yakni tahun 2008 dilakukan hingga saat ini pasangan yang melakukan perkawinan Pada Gelahang tidak ada yang memiliki permasalahan. Selain itu dari data tahun 2008 , belum ada yang mengakhiri perkawinan Pada gelahang yang dilaksanakan.

Prof Windia menyebutkan jika sistem perkawinan Pada Gelahang akan menjadi sistem perkawinan alternatif di Bali khususnya bagi anak pasangan suami istri yang memiliki anak tunggal. "Hal ini tidak bisa dilepaskan dari adanya pengauruh modernisasi, dan adanya kemajuan di 
bidang pendidikan, sehingga semakin menumbuhkan kesadaran masyarakat tentang perlunya sistem perkawinan ini untuk diterapkan," paparnya.

Persepsi masyarakat terhadap perkawinan pada gelahang pada dasarnya berada dalam kategori positif, karena faktanya sudah banyak dilakukan oleh masyarakat, dan sesuai dengan sastra suci Hindu. Sistem pewarisan dalam keluarga yang melaksanakan perkawinan pada gelahang di Bali pada dasarnya menganut asas parental, yaitu sistem pewarisan yang mewarisi pihak keluarga laki-laki dan keluarga perempuan secara bersama-sama (seimbang). Sistem ini menggambarkan terjadinya pergeseran dari sistem patrilineal ke sistem parental. Perubahan ini didasarkan pada kemajuan pendidikan masyarakat, sehingga lebih mengedepankan kesetaraan, kepekaan, keadilan gender, kesadaran akan peng-hargaan harkat dan martabat manusia, termasuk kesadaran dalam melaksanakan hak asasi manusia (HAM). Menenai pola pengasuhan anak dalam keluarga yang terbentuk melalui perkawinan pada gelahang di Bali pada umumnya memilih pola asuhan demokratis yang dicirikan dengan adanya hak dan kewajiban orang tua dan anak adalah sama, dalam arti mereka saling melengkapi. Hal ini ditegas-kan oleh I Nyoman Nada (pasangan yang melangsungkan perkawinan Pada Gelah-ang). Dalam keluarga Bapak I Nyoman Nada, secara perlahan tetapi pasti menga-jak anak-anaknya untuk bertanggung jawab dan menentukan perilaku sendiri untuk mencapai kedewasaan. Tindakan dan perilaku Bapak I Nyoman Nada selalu disampaikan dengan alasan dan tujuan untuk saling membantu dan saling penuh pengertian.

Proses upacara (pabyakaonan) dalam perkawinan pada gelahang dilaksa-nakan di dua tempat, yaitu di rumah kediaman istri dan di rumah kediaman suami, yang sama-sama dihadiri oleh keluarga dan masyarakat.
Di sisi lain, perkawinan nyentana juga dinilai sebagai salah satu bentuk perkawinan alternatif yang bisa menye-lamatkan keluarga-keluarga yang tidak memiliki anak laki-laki. Dengan mengambil bentuk perkawinan nyentana, anak perempuan dapat dikukuhkan statusnya sebagai laki-laki (purusa) yang dapat meneruskan keturunan, sehingga mereka dapat terhindar dari keluarga putus (cepung). Meskipun demikian, keputusan untuk melakukan perkawinan nyentana harus dipertimbangkan terlebih dahulu secara matang oleh keluarga-keluarga nyentana. Selain mempertimbangkan unsur sama-sama cinta, pihak mempelai laki-lakijuga harus mempertimbangkan untuk melepaskan status laki-laki (purusa) dan menerima status sebagai perempuan (predana). Demikian juga pihak mempelaigelahang di Bali pada umumnya memilih pola asuhan demokratis yang dicirikan dengan adanya hak dan kewajiban orang tua dan anak adalah sama, dalam arti mereka saling melengkapi. Hal ini ditegaskan oleh I Nyoman Nada (pasangan yang melangsungkan perkawinan Pada Gelah-ang). Dalam keluarga Bapak I Nyoman Nada, secara perlahan tetapi pasti menga-jak anak-anaknya untuk bertanggung jawab dan menentukan perilaku sendiri untuk mencapai kedewasaan. Tindakan dan perilaku Bapak I Nyoman Nada selalu disampaikan dengan alasan dan tujuan untuk saling membantu dan saling penuh pengertian.

Proses upacara (pabyakaonan) dalam perkawinan pada gelahang dilaksa-nakan di dua tempat, yaitu di rumah kediaman istri dan di rumah kediaman suami, yang sama-sama dihadiri oleh keluarga dan masyarakat.

Di sisi lain, perkawinan nyentana juga dinilai sebagai salah satu bentuk perkawinan alternatif yang bisa menye-lamatkan keluarga-keluarga yang tidak memiliki anak laki-laki. Dengan mengambil bentuk perkawinan nyentana, anak perempuan dapat dikukuhkan statusnya sebagai laki-laki (purusa) yang dapat meneruskan keturunan, sehingga mereka dapat terhindar dari keluarga 
putus (cepung). Meskipun demikian, keputusan untuk melakukan perkawinan nyentana harus dipertimbangkan terlebih dahulu secara matang oleh keluarga-keluarga nyentana. Selain mempertimbangkan unsur sama-sama cinta, pihak mempelai laki-lakijuga harus mempertimbangkan untuk melepaskan status laki-laki (purusa) dan menerima status sebagai perempuan (predana).

Konskuensi logis perkawinan pada gelahang adalah perubahan status kekelu-argaan dari kebapaan/purusa menjadi kebapaan dan ibu secara bersama-sama, yang sering disebut parental. Dalam arti bahwa suami dan istri mempunyai hak dan kewajiban yang sama baik di rumah suami dan di rumah si istri sehingga sering disebut tanggung bersama-sama (negen dadua). Demikian juga status anak-anak/keturunan mempunyai kewajiban dan hak sama baik di rumah kediaman ibunya dan di rumah kediaman bapaknya. Hak hak dan kewajiban itu dapat berupa penerus keturunan, sebagai ahli waris, dan bertanggung jawab terhadap tempat sembahyang yang ada di rumah ibunya dan di rumah bapaknya.

Meningkatnya kecenderungan ma-syarakat Bali melaksanakan perkawinan pada gelahang, sebagai perkawinan alter-natif, telah diperkuat dengan Paruman Sulinggih dan Paruman Walaka Pengurus Parisada Hindu Dharma Indonesia Provinsi Bali yang menegaskan bahwa perkawinan pada gelahang sesuai dengan ajaran agama Hindu dan Hukum Adat Bali. Hal ini memberikan indikasi bahwa kesa-daran terhadap kesetaraan dan keadilan gender, penghargaan terhadap harkat dan martabat manusia, penghargaan terhadap hak asasi manusia (HAM), serta kesadar-an untuk mendapat keturunan untuk mewarisi warisan berupa material dan immaterial semakin meningkat.

\section{SIMPULAN DAN SARAN}

Perkawinan Pada Gelahang sudah menjadi alternative pilihan bagi kedua pihak keluaraga jika karena suatu kondisi tidak dapat dilangsungkannya system Purusa maupun Nyentana. Pada Gelahang hadir dengan berbagai opsi yang dapat ditentukan demi keuntungan kedua pihak mempelai sehingga tidak akan terjadi hal yang tidak diinginkan kedua belah pihak di kemudian hari. Pada jaman sekaranga yang semakin mdern system ini sesingguhnya telah banyak digunakan walaupun tidak ada perjanjian secara tertulis tapi dengan toleransi tinggi dari pihak baik Pria maupun wanita sehingga hampir tidak adanya batasan yang benar benar mengikat terutama pihak wanita di keluarga pengantin pria.

Proses perkawinan pada gelahang tidak jauh berbeda dengan proses perka-winan biasa, yaitu dilaksanakan dengan proses meminang/ memadik, yang sebe-lumnya diawali dengan masa pacaran. Proses upacara dalam perkawinan biasa, umumnya keluarga laki-laki relatiflebih sibuk bila dibandingkan dengan keluarga perempuan. Sedangkan proses upacara perkawinan pada gelahang relatif seim-bang antara pihak keluarga laki-laki dan pihak keluarga perempuan. Keseimbang-an ini ditandai dengan adanya upacara yang sama di rumah mempelai laki-laki dan mempelai perempuan. Artinya, dalam perkawinan pada gelahang ada dua kali upacara yang relatif sama, antara di rumah mempelai lakilaki dan di rumah mempelai perempuan.

Dengan asas keadilan sekarang yang tinggi dan emansipasi wanita yang semakin digalakkan menjadikan system perkawinan pada gelahang menjadi system yang sangat tepat dan efisien digunakan saat ini. Selain itu akan memupuk rasa saling memiliki antara keluaga pengantin pria maupun keluarga pengantin wanita. Diharapkan penggunaan site mini dapat berkembang sebaik mungkin sehingga menjadi system perkawinan yang tidak merugikan sebelah pihak melainkan menjadi system yang membangun rasa keharmonisan dan kedamaian dalam kehidupan berkeluarga maupun bermasyarakat. 


\section{DAFTAR PUSTAKA}

Bagus. I Gustu Ngurah. 1971. Sistem Pola Menetap Masyarakat Bali. Denpasar: UNUD Denpasar.

Carspecken, P.F. 1998. Critical Ethno-grapyin Educational Research: A theoriticaland practical guide. London and New York: Routledge.

Depdagri. 1992. Pembinaan Lembaga Adat di Desa dan Kelurahan, Jakarta: Depdagri.

Danandjaja, James. 1977. Pengasuhan Anak, Kebudayaan Desa Trunyan di Bali, Jakarta: Disertasi F.S UI.

Harian Umum Bali Post, Tanggal 20 Juli 2008:

"Negen Dadua Mapanak Bareng Alternatif Perkawinan di Bali"

Harian Umum Bali Post, Tanggal 10 Oktober 2008: "Dianggap Tidak Sah, Perkawinan "”Negen” Digugat Ibu Tiri" Harian Umum Bali Post, Tanggal 13 Oktober 2008: " Perkawinan "Negen” Sah dalam Hukum Hindu.

Windia, Wayan P. 2009. Perkawinan Pada Gelahang di Bali. Denpasar: Udayana University Press. 